\title{
Conversion of furan derivatives for preparation of biofuels over $\mathrm{Ni}-\mathrm{Cu} / \mathrm{C}$ catalyst
}

\author{
Fu, Zhaolin; Wang, Z.; Lin, Weigang; Song, Wenli
}

Published in:

Energy Sources. Part A. Recovery, Utilization, and Environmental Effects

Link to article, DOI:

10.1080/15567036.2017.1310959

Publication date:

2017

Document Version

Peer reviewed version

Link back to DTU Orbit

\section{Citation (APA):}

Fu, Z., Wang, Z., Lin, W., \& Song, W. (2017). Conversion of furan derivatives for preparation of biofuels over Ni$\mathrm{Cu} / \mathrm{C}$ catalyst. Energy Sources. Part A. Recovery, Utilization, and Environmental Effects, 39(11), 1176-1181. https://doi.org/10.1080/15567036.2017.1310959

\section{General rights}

Copyright and moral rights for the publications made accessible in the public portal are retained by the authors and/or other copyright owners and it is a condition of accessing publications that users recognise and abide by the legal requirements associated with these rights.

- Users may download and print one copy of any publication from the public portal for the purpose of private study or research.

- You may not further distribute the material or use it for any profit-making activity or commercial gain

- You may freely distribute the URL identifying the publication in the public portal 


\title{
Conversion of furan derivatives for preparation of biofuels over $\mathrm{Ni}-\mathrm{Cu} / \mathrm{C}$ catalyst
}

\author{
Zhaolin Fu ${ }^{a, b}$, Ze Wang ${ }^{a, b}$, Weigang Lin ${ }^{a, b, c}$, and Wenli Song ${ }^{a, b}$ \\ aState Key Laboratory of Multi-Phase Complex Systems, Institute of Process Engineering, Chinese Academy of

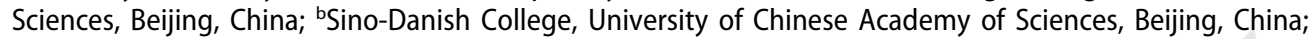 \\ 'Department of Chemical and Biochemical Engineering, Technical University of Denmark, Lyngby, Denmark
}

\begin{abstract}
Conversions of furfural and 5-hydroxymethylfurfural as model components in bio-oil were investigated over $\mathrm{Ni}-\mathrm{Cu} / \mathrm{C}$ catalyst with formic acid as hydrogen donor in isopropanol solvent to produce biofuels. The effects of reaction temperature, feed ratio, and reaction time were studied. A high yield of 2-methylfuran up to $91 \mathrm{~mol} \%$ was obtained from furfural in $8 \mathrm{~h}$ at $200^{\circ} \mathrm{C}$, and under same conditions $80 \mathrm{~mol} \%$ yield of 2,5-dimethylfuran could also be obtained from 5hydroxymethylfurfural in $6 \mathrm{~h}$. The results verified the catalyst performance and the availability of the reaction conditions for producing biofuels from furan derivatives.
\end{abstract}

\section{KEYWORDS}

Biofuel; 2,5-dimethylfuran; furfural; hydrogen donor; 5-hydroxymethylfurfural; 2-methylfuran

\section{Introduction}

With the continuous diminishing of fossil resources, the development of biomass resource is quite urgent and promising (Huber et al., 2006). Furfural (FU) and 5-hydroxymethylfurfural (HMF) are two abundant furan derivatives in bio-oil (Demirbas, 2006; Huber et al., 2006; Hassan et al., 2009). Particularly, FU is regarded as one of the top 10 biorefinery building chemicals (Bozell and Petersen, 2010), since FU can be widely used to produce fuels and chemicals such as furan, furfural alcohol (FOL), 2-methylfuran (2-MF), tetrahydrofuran (THF), and cyclopentanone. as shown in Scheme 1 (Pushkarev et al., 2012; Bohre et al., 2015). Among the products, 2-MF can be used as a fuel additive with high research octane number $(103>97$ of gasoline) and adequate energy density $(28.5 \mathrm{MJ} / \mathrm{L}>$ 21.0 MJ/L of ethanol) (Bohre et al., 2015). Due to the high activity of FU, a high yield of 2-MF is usually hard to be achieved under mild conditions. At present, the highest 2-MF yield is $95.5 \mathrm{~mol} \%$ over $\mathrm{Cu} / \mathrm{SiO}_{2}$ catalyst with a high $\mathrm{H}_{2}$ to vaporous furfural ratio of 17:1 (Dong et al., 2016). However, the application of gaseous $\mathrm{H}_{2}$ causes severe challenges in securities of storage and operation.

Therefore, in-situ hydrodeoxygenation process is put forward (Xu et al., 2015), where the hydrogen source is offered from hydrogen donors such as formic acid, methanol, and isopropanol. Activated carbon-supported $\mathrm{Ni}-\mathrm{Cu}$ catalyst, with the advantage of low price, has been proved effective in producing FOL from conversion of FU in isopropanol solvent (Reddy Kannapu et al., 2015). However, FOL is not a qualified biofuel due to its low heat value and relative high oxygen content. Therefore, the conversion of $\mathrm{FU}$ over $\mathrm{Ni}-\mathrm{Cu} / \mathrm{C}$ in isopropanol solvent is investigated to enhance the product selectivity to 2-MF, with a stronger hydrogen donor of formic acid. Furthermore, the availability of the optimized catalytic reaction conditions to the conversion of HMF to 2,5-dimethylfuran (DMF) is also tested, since DMF is also a good fuel additive with research octane number (101) and high energy density (29.3 MJ/L) (Bohre et al., 2015).

CONTACT Ze Wang wangze@ipe.ac.cn @ State Key Laboratory of Multi-Phase Complex Systems, Institute of Process Engineering, Chinese Academy of Sciences, Beijing, China.

Color versions of one or more of the figures in the article can be found online at www.tandfonline.com/ueso. 


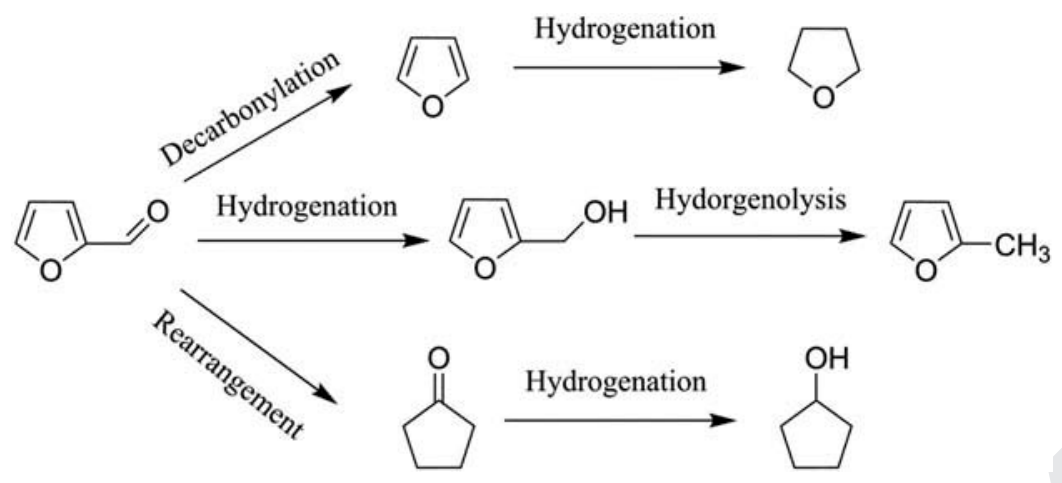

Scheme 1. The potential reaction pathways of furfural.

\section{Experimental section}

The bimetallic catalyst $10 \% \mathrm{Ni}-10 \% \mathrm{Cu} / \mathrm{C}$ was prepared by incipient wetness impregnation method: $0.55 \mathrm{~g} \mathrm{Ni}\left(\mathrm{NO}_{3}\right)_{2} \cdot 6 \mathrm{H}_{2} \mathrm{O}$ (Sinopharm, $\geq$ inopha and $0.42 \mathrm{~g} \mathrm{Cu}\left(\mathrm{NO}_{3}\right) \cdot 3 \mathrm{H}_{2} \mathrm{O}$ (Sinopharm, $\geq$ (Sinop were dissolved in $2.5 \mathrm{~g}$ deionized water; and then impregnated on $1 \mathrm{~g}$ activated carbon (Sinopharm, mean particle size: $55-65 \mu \mathrm{m}$, surface area: $715 \mathrm{~m}^{2} / \mathrm{g}$, average pore size: $2.51 \mathrm{~nm}$, and measured by $\mathrm{N}_{2}$ physisorption), aging for $10 \mathrm{~h}$ at room temperature; then, the sample was dried at $80^{\circ} \mathrm{C}$ for $10 \mathrm{~h}$ and calcined at $500^{\circ} \mathrm{C}$ for $5 \mathrm{~h}$ under $\mathrm{N}_{2}$ atmosphere; finally, the sample was reduced at $550^{\circ} \mathrm{C}$ for $2 \mathrm{~h}$ in a reduction atmosphere ( $50 \mathrm{vol} \% \mathrm{H}_{2}$ and $\left.50 \mathrm{vol} \% \mathrm{Ar}, 300 \mathrm{~mL} / \mathrm{min}\right)$.

The experiments on conversion of FU were conducted in a $100 \mathrm{~mL}$ autoclave (C276 Hastelloy, CJF-0.1 L). In each run, the catalyst of $10 \% \mathrm{Ni}-10 \% \mathrm{Cu} / \mathrm{C}(0.05-0.2 \mathrm{~g})$, FU (0.5-2 g), formic acid (0-4 $\mathrm{g}$ ), and isopropanol $(10 \mathrm{~g})$ were loaded into the reactor. Before heating, the reactor was flushed by $\mathrm{N}_{2}$ three times and then remained at $1 \mathrm{MPa}$. The reactor was then heated to $180-260^{\circ} \mathrm{C}$ and kept for $1-7$ h. The liquid product was analyzed by GC-MS (Varian 320GC/300MS) and quantified through internal standard method using ethylene glycol as the standard substance.

\section{Results and discussion}

\subsection{Effect of reaction temperature on furfural conversion and product yields}

The conversions of FU under different temperatures are shown in Figure 1. It could be seen that the conversion of FU increased rapidly with increasing temperature in low temperatures and then became stable around $97 \mathrm{~mol} \%$ above $200^{\circ} \mathrm{C}$. The product distribution remarkably changed with varied temperatures. Furan from decarbonylation of $\mathrm{FU}$ was more generated at higher temperatures since it is an endothermic process (Pushkarev et al., 2012). THF and butanol, respectively, derived from deep hydrogenation and ring-opening conversion of furan, were more generated at high temperatures as well, making the product distribution complex. The yield of FOL decreased with increasing temperature, since FOL would further convert to 2-MF by hydrogenolysis at higher temperatures. However, the decarbonylation of $\mathrm{FU}$ became more prevalent at higher temperatures too, so a maximum 2-MF yield of $65.5 \mathrm{~mol} \%$ appeared at middle $220^{\circ} \mathrm{C}$. In general, from the perspective of high yield of $2-\mathrm{MF}$ with low energy cost, $200^{\circ} \mathrm{C}$ was the optimal temperature in this reaction system.

\subsection{Effect of feed ratios on furfural conversion and product yields}

The conversion of FU and product yields varied with mass ratios of catalyst to FU to formic acid was investigated as shown in Table 1. It could be seen that the conversions of FU were generally all above 


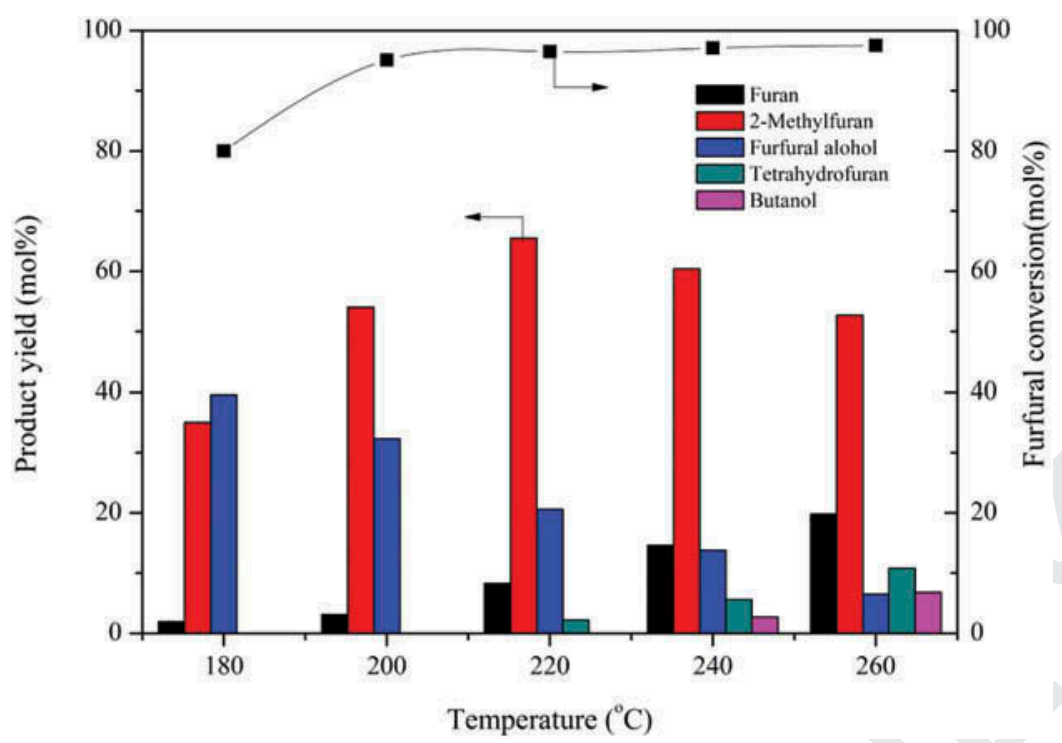

Figure 1. Furfural conversions and product yields under different reaction temperatures. Feedstock: $1 \mathrm{~g}$ furfural, $2 \mathrm{~g}$ formic acid, 10 $\mathrm{g}$ isopropanol, $0.1 \mathrm{~g}$ catalyst, and reaction time $=4 \mathrm{~h}$.

Table 1. Furfural conversion and product yields varied with different feedstock ratios over $\mathrm{Ni}-\mathrm{Cu} / \mathrm{C}$ catalyst.

\begin{tabular}{|c|c|c|c|c|c|c|}
\hline \multirow[b]{2}{*}{ Entry } & \multirow[b]{2}{*}{ Mcat.:M $\mathrm{MU}_{\mathrm{Fu}}: \mathrm{M}_{\mathrm{acid}}$} & \multirow[b]{2}{*}{ FU Conversion } & \multicolumn{4}{|c|}{ Yield } \\
\hline & & & Furan & 2-MF & $\mathrm{FOL}$ & Butanol \\
\hline 1 & $0.1: 1: 0$ & 82.7 & 2.8 & 3.4 & 75.1 & 0.0 \\
\hline 2 & $0.1: 1: 1$ & 93.4 & 3.0 & 35.6 & 53.1 & 0.0 \\
\hline 3 & $0.1: 1: 2$ & 95.1 & 3.1 & 57.6 & 32.3 & 0.0 \\
\hline 4 & $0.1: 1: 4$ & 97.5 & 4.6 & 66.2 & 22.1 & 2.5 \\
\hline 5 & $0.05: 1: 2$ & 83.3 & 2.3 & 36.1 & 44.4 & 0.0 \\
\hline 6 & $0.2: 1: 2$ & 100.0 & 4.1 & 59.4 & 31.2 & 2.4 \\
\hline 7 & $0.1: 2: 2$ & 79.7 & 3.6 & 31.4 & 42.1 & 0.0 \\
\hline 10 & $0.1: 0.5: 2$ & 98.1 & 4.4 & 70.4 & 20.4 & 2.7 \\
\hline
\end{tabular}

Reaction time: $4 \mathrm{~h}$, reaction temperature: $200^{\circ} \mathrm{C}$, FU: furfural, 2-MF: 2-methylfuran, FOL: furfural alcohol.

$80 \%$, and a high catalyst proportion favored the increase of FU conversion. FOL and 2-MF were two major products, while the yields of furan and butanol were rather low for all cases. If no formic acid was added, a high FOL yield of $75.1 \mathrm{~mol} \%$ was achieved. With increasing proportion of formic acid the selectivity to 2-MF increases remarkably, while the yield of FOL decreased reversely. It indicates hydrogenation of FU to FOL can happen even with no formic acid, which could be attributed to the hydrogen donating conversion of isopropanol with the formation of acetone (Gilkey et al., 2015). However, the hydrogen donation capacity of isopropanol is relatively weak for further hydrogenolysis of the hydroxyl group, and with the addition of more formic acid as a stronger hydrogen donor (Zeng et al., 2016), furfural alcohol was more converted to 2-methylfuran. Generally, Mcat.: $\mathrm{M}_{\mathrm{FAL}}$ : $\mathrm{M}_{\mathrm{acid}}=0.1: 1: 2$ was the optimal ratio for maximizing the yield of 2-methylfuran at $200^{\circ} \mathrm{C}$.

\subsection{Effect of reaction time on furfural conversion and product yields}

The influence of reaction time was investigated as shown in Figure 2. It could be seen that FU was completely consumed in $8 \mathrm{~h}$ and the conversion proceeded faster in the early $4 \mathrm{~h}$. The yield of furan just kept in low level. The yield of FOL increased with evolution of the reaction in early stage and 


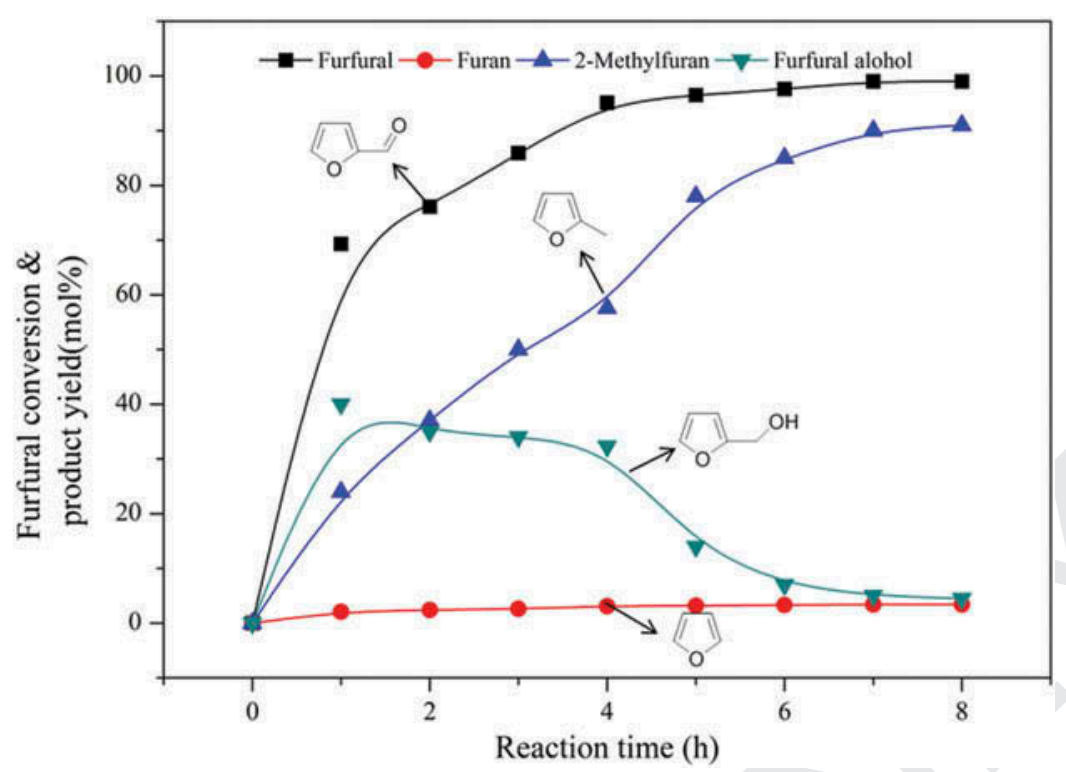

Figure 2. The furfural conversion and product yields with varied reaction time over $10 \% \mathrm{Ni}-10 \% \mathrm{Cu} / \mathrm{C}$ at $200^{\circ} \mathrm{C}$. Feedstock: $1 \mathrm{~g}$ furfural, $2 \mathrm{~g}$ formic acid, $10 \mathrm{~g}$ isopropanol, and $0.1 \mathrm{~g}$ catalyst.

then became nearly stable in middle stage and finally transformed to a declining trend. Correspondingly, the yield of 2-MF monotonously increased with prolonging of the reaction time in the first $6 \mathrm{~h}$, with the highest 2-MF yield of $91 \mathrm{~mol} \%$ at the end of reaction with the consecutive reaction mechanism for FOL as intermediate (Gilkey et al., 2015).

\subsection{Effect of reaction time on 5-hydroxymethylfurfural conversion and product yields}

Since HMF was another significant furan derivative in bio-oil with similar molecular structure and chemical properties to FU (Huber et al., 2006), the prior optimized reaction conditions were therefore tested for the conversion of HMF for preparation of DMF. The results are shown in Figure 3. Due to the more active functional groups in HMF, the product distribution was more complex. It showed the decreasing trend of HMF conversion, the monotonous increasing trend of DMF, and the arch-shape variation of the carbonyl reduction products of 2,5-bis-hydroxymethylfuran (BHMF) and 5-methyl furfural alcohol (MFA). The yield of others, consisting of 2-MF, FOL, and 5-methylfurfural, was augmented under longer reaction times, which could be an explanation for the slow increasing rate of DMF at longer times. The yield of DMF reached up to $80 \mathrm{~mol} \%$ in $6 \mathrm{~h}$, verified the availability of the catalyst with optimized reaction conditions for generation of DMF from conversion of HMF. There could be two reaction routes for the formation of DMF from HMF (Shi et al., 2016). The first one is that DMF was derived from hydrogenation of the carbonyl group, followed by consecutive hydrolysis of the obtained BHMF as intermediates. In the second route, DMF was generated from first hydrogenolysis of the hydroxyl group in HMF with 5-methylfurfural as the intermediate, followed by total reduction of the carbonyl group. Herein, the obtained product distribution indicated that DMF was predominantly derived from the first route rather than the second one under present catalytic reaction conditions, since only a little amount of 5-methylfurfural was detected in the liquid. 


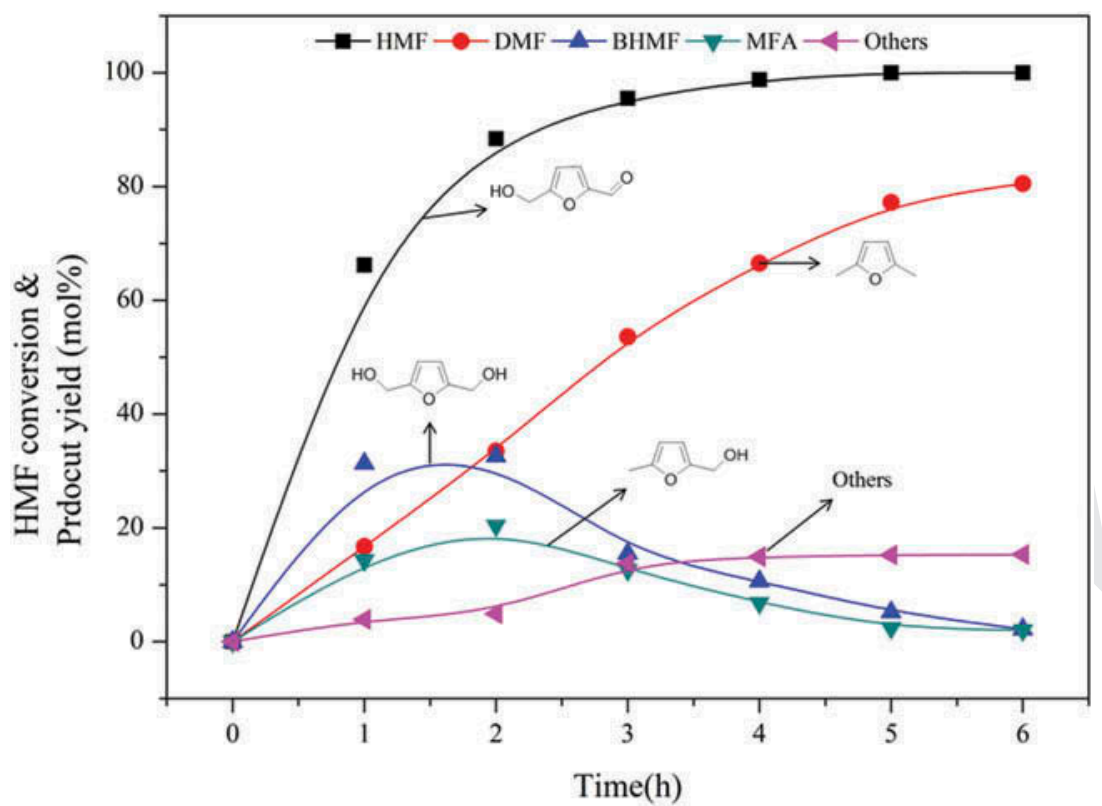

Figure 3. The conversion of $\mathrm{HMF}$ and the product yield with reaction time over $10 \% \mathrm{Ni}-10 \% \mathrm{Cu} / \mathrm{C}$ at $200^{\circ} \mathrm{C}$ with formic acid as the hydrogen donor. HMF: 5-hydroxymethylfurfural; DMF: 2,5-dimethylfuran, BHMF: 2,5-bis-hydroxymethylfuran, MFA: 5-methyl furfural alcohol. Others include 2-methylfuran, furfural alcohol, 5-methylfurfural. Feedstock: $1 \mathrm{~g} \mathrm{HMF,} 2 \mathrm{~g}$ formic acid, $10 \mathrm{~g}$ isopropanol, and $0.1 \mathrm{~g}$ catalyst.

\section{Conclusions}

Conversions of $\mathrm{FU}$ and $\mathrm{HMF}$ as model components in bio-oil were investigated over $\mathrm{Ni}-\mathrm{Cu} / \mathrm{C}$ catalyst with formic acid as hydrogen donor in isopropanol solvent. A higher temperature was found promotive to the conversion of $\mathrm{FU}$ but with complex product distribution. Isopropanol could promote the hydrogenation of carbonyl group with the formation of FOL. The existence of formic acid could further enhance the hydrogenolysis of FOL to 2-MF. The high yield of 2-MF up to $91 \mathrm{~mol}$ $\%$ was obtained in $8 \mathrm{~h}$ at $200^{\circ} \mathrm{C}$, and under same conditions DMF could also be obtained from HMF with $80 \mathrm{~mol} \%$ high yield in $6 \mathrm{~h}$, which verified the high catalyst performance and the availability of the reaction conditions for conversion of furan derivatives to biofuels.

\section{Funding}

This work was supported by the National Natural Science Foundation of China (51476180).

\section{References}

Bohre, A., Dutta, S., Saha, B., and Abu-Omar, M. M. 2015. Upgrading furfurals to drop-in biofuels: An overview. ACS Sustain. Chem. Eng. 3:1263-1277. DOI: 10.1021/acssuschemeng.5b00271.

Bozell, J. J., and Petersen, G. R. 2010. Technology development for the production of biobased products from biorefinery carbohydrates-The US Department of Energy's "Top 10" revisited. Green Chem. 12:539. DOI: $10.1039 / \mathrm{b} 922014 \mathrm{c}$.

Demirbas, M. F. 2006. Current technologies for biomass conversion into chemicals and fuels. Energy Sour., Part. 28:1181-1188. DOI: 10.1080/00908310500434556.

Dong, F., Ding, G., Zheng, H., Xiang, X., Chen, L., Zhu, Y., and Li, Y. 2016. Highly dispersed Cu nanoparticles as an efficient catalyst for the synthesis of the biofuel 2-methylfuran. Catal. Sci. Technol. 6:767-779. DOI: 10.1039/ C5CY00857C. 
Gilkey, M. J., Panagiotopoulou, P., Mironenko, A. V., Jenness, G. R., Vlachos, D. G., and Xu, B. 2015. Mechanistic insights into metal Lewis acid-mediated catalytic transfer hydrogenation of furfural to 2-Methylfuran. ACS Catal. 5:3988-3994. DOI: 10.1021/acscatal.5b00586.

Hassan, E. M., Steele, P. H., and Ingram, L. 2009. Characterization of fast pyrolysis bio-oils produced from pretreated pine wood. Appl. Biochem. Biotechnol. 154:3-13. DOI: 10.1007/s12010-008-8445-3.

Huber, G. W., Iborra, S., and Corma, A. 2006. Synthesis of transportation fuels from biomass: Chemistry, catalysts and engineering. Chem. Rew. 106:4044-4098. DOI: 10.1021/cr068360d.

Pushkarev, V. V., Musselwhite, N., An, K., Alayoglu, S., and Somorjai, G. A. 2012. High structure sensitivity of vaporphase furfural decarbonylation/hydrogenation reaction network as a function of size and shape of Pt nanoparticles. Nano. Lett. 12:5196-5201. DOI: 10.1021/nl3023127.

Reddy Kannapu, H. P., Mullen, C. A., Elkasabi, Y., and Boateng, A. A. 2015. Catalytic transfer hydrogenation for stabilization of bio-oil oxygenates: Reduction of p-cresol and furfural over bimetallic Ni-Cu catalysts using isopropanol. Fuel Process. Technol. 137:220-228. DOI: 10.1016/j.fuproc.2015.04.023.

Shi, J., Wang, Y., Yu, X., Du, W., and Hou, Z. 2016. Production of 2,5-dimethylfuran from 5-hydroxymethylfurfural over reduced graphene oxides supported Pt catalyst under mild conditions. Fuel. 163:74-79. DOI: 10.1016/j. fuel.2015.09.047.

Xu, Y., Long, J., Liu, Q., Li, Y., Wang, C., Zhang, Q., Lv, W., Zhang, X., Qiu, S., Wang, T., and Ma, L. 2015. In situ hydrogenation of model compounds and raw bio-oil over Raney Ni catalyst. Energy Convers. Manage. 89:188-196. DOI: 10.1016/j.enconman.2014.09.017.

Zeng, Y., Wang, Z., Lin, W., Song, W., Christensen, J. M., and Jensen, A. D. 2016. Hydrodeoxygenation of phenol over Pd catalysts by in-situ generated hydrogen from aqueous reforming of formic acid. Catal. Commun. 82:46-49. DOI: 10.1016/j.catcom.2016.04.018. 